\title{
Geração Millennials: Como capta e valoriza a comunicação do recurso turístico
}

\author{
Millennials generation: How to capture and value the communication of tourist \\ resources
}

\author{
Pedro Alves Trindade \\ Escola Superior de Hotelaria e Turismo do Estoril \\ pedro.trindade@eshte.pt
}

\begin{abstract}
Resumo
Geração Millennials, com elevada representatividade na economia e no turismo nacional e internacional, é também responsável por uma elevada taxa de utilização da Web e das novas tecnologias. A Web abriu novas perspetivas à sociedade e em particular aos Millennials, é por isso fundamental que os recursos turísticos correspondam com informação para os seus públicos. Neste trabalho, pretende-se identificar o que a Geração Millennials portuguesa valoriza, aquando da viagem turística, e como a Web e as redes sociais influenciam a escolha/experiência com determinado recurso turístico. Desta forma, ambiciona-se contribuir para um maior conhecimento sobre os Millennials, e como estes interpretam a comunicação veiculada na Web, concluindo que as redes sociais podem influenciar a escolha/experiência de determinado recurso turístico.
\end{abstract}

Palavras-chave: turismo; millennials; comunicação; web; recurso turístico; gerações.

\begin{abstract}
The 'millennials' generation, with a high level of representation in both the economy and national and international tourism, also accounts for a high rate of usage of the worldwide web and innovative technologies. The web has opened up new perspectives for society, and in particular for the millennials, making it therefore fundamental that tourist resources correspond with information for their public. We aim to identify what the Portuguese Millennials generation most value, during tourist trips, and how the web and social media influence the choice of/experience with a particular tourist resource. In this way, we hope to contribute to a greater knowledge about millennials and how they interpret communication transmitted via the web, concluding that social media can influence their choice of/experience with a particular tourist resource.
\end{abstract}

Keywords: tourism; millennials; communication; web; tourist resources; generations.

\section{Introdução}

As alterações da sociedade são, frequentemente, o motivo de alterações significativas nas organizações e nas políticas globais. Estas promovem uma constante adequação a novos públicos, consumidores e realidades, na busca de um sustentado crescimento. O turismo, nos últimos anos, não fugiu a esta generalização sendo uma atividade com um elevado crescimento.

De acordo com o último Barómetro da Organização Mundial do Turismo (OMT) (2015), as chegadas de turistas internacionais subiram 4,3\% nos primeiros oito meses de 2015, e o número de turistas internacionais chegou aos 810 milhões no mesmo período, o que significa um aumento de 33 milhões relativo ao período homólogo de 2014.

Portugal acompanhou este crescimento e é hoje, segundo Tadeu (2015), considerado um destino com elevado nível de segurança, com uma excelente relação qualidade/preço, para além do sempre reconhecido clima de excelência, simpatia e boa gastronomia.

Dos Algarves: A Multidisciplinary e-Journal, 31- 2017.

ISBN 2182-5580 @ ESGHT - University of the Algarve, Portugal.

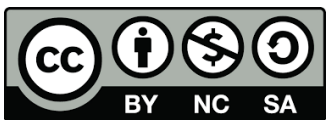

To cite this article: P.A. Trindade (2017). Geração Millennials: Como capta e valoriza a comunicação do recurso turístico. Dos Algarves: A Multidisciplinary e-Journal, 31, 98-118. doi: 10.18089/DAMeJ.2017.31.7 
Pode dizer-se que o desenvolvimento do turismo é comparável ao protagonizado pela Web. Com um crescimento constante, a Web é hoje garantia de suporte comercial e de comunicação, para as mais variadas organizações ou setores de atividade existentes.

A crescente procura que se verifica no setor do turismo, promovida por razões tão diversas como a procura de novos destinos, produtos ou recursos, é hoje fortalecida pela ajuda significativa de uma Web cada vez mais global e efetiva.

A Web, no seu todo, torna-se o meio de comunicação preferencial dos destinos turísticos (Kim \& Fesenmaie, 2008: 6). Um conceito que está presente nos marketers que trabalham, a nível mundial, no setor do turismo e que, desta forma, promovem o seu desenvolvimento estratégico (Park \& Gretzel, 2007: 47).

O conteúdo do site de um destino turístico, entendido como um conjunto de produtos turísticos que oferecem uma experiência integrada para os consumidores (Buhalis, 2000: 97), influencia diretamente a imagem percecionada e possibilita a criação de uma experiência virtual ao consumidor (Doolin, Bourgess \& Cooper, 2002: 557).

É neste cenário que se foca o objetivo desta investigação que pretende identificar o comportamento da Geração Millennials. Jovens com uma atitude diferenciadora no contexto do turismo e que vivem numa permanente relação com as novas tecnologias e a Web.

Na sequência desta pretensão, considerou-se importante estudar o conceito de geração, a Web, referenciando a importância das redes sociais enquanto ferramenta de comunicação, e o turismo, numa mais direta abordagem ao recurso turístico, ou seja, todos os bens e serviços que tornam possível a atividade turística e satisfazem as necessidades da procura (Cunha, 2009: 263).

Neste sentido, após a revisão bibliográfica, descreve-se o estudo empírico com recurso à aplicação de um inquérito por questionário por forma a avaliar se a nossa amostra, que face à metodologia utilizada não permite a extrapolação desejável à Geração Millennials portuguesa, integra os desejos/intenções referenciados pela generalizada literatura.

Tendo como objeto de estudo a comunicação no turismo, questiona-se enquanto problema de investigação, a forma como a Geração Millennials portuguesa se identifica com a Web na sua relação com o recurso turístico. Neste sentido, enquanto pergunta de partida, pretendemos identificar o que é valorizado pela Geração Millennials portuguesa aquando da viagem turística e como é que a Web, em geral, e as redes sociais, em particular, podem influenciar na escolha ou na experiência com determinado recurso turístico.

Para tal, foram consideradas as seguintes hipóteses:

H1: A permanente utilização da internet em viagem é fundamental para a Geração Millennials;

H2: As viagens têm de apresentar uma forte componente experiencial;

H3: As redes sociais são fundamentais para a partilha de informação com amigos;

H4: Recorrer à Web para identificar/explorar recursos é determinante durante a viagem;

H5: Conhecer novos lugares/experiências é fator determinante para a viagem;

H6: A internet foi determinante na escolha do recurso que pretendia visitar.

\section{Desenvolvimento geracional}

Quando se analisam as mais diversas gerações, temos consciência de que nada é igual. Estabelecendo uma relação entre gerações e consumidores, facilmente se chega ao conceito 
de segmentação. Para Kotler (1980: 250), a segmentação de mercado é uma etapa fundamental no processo de estratégia de marketing. Já Solomon (2006: 12) explica o conceito de segmentação de forma um pouco mais complexa, referindo-se à mesma como a delimitação de segmentos de consumidores cujos membros detenham semelhanças entre si em uma ou mais características que os diferencie de outros grupos. No entanto, é Schiffman, Kanuk e Wisenblit (2010: 11) que, através de um modelo de segmentação, apoiado no estudo de Wisenblit, melhor definem este complexo processo. Os autores cruzam variáveis factuais com base nos consumidores e no consumo com variáveis de origem cognitiva centradas na personalidade, estilo de vida e valores socioculturais também dos consumidores, bem como nas atitudes e preferências relativas ao produto (Tabela 1).

Tabela 1. Bases de segmentação de Wisenblit

\begin{tabular}{|c|c|c|}
\hline & Centrado no Consumidor & Centrado no Consumo \\
\hline & $\begin{array}{l}\text { Características pessoais } \\
\text { empíricas/demográficas }\end{array}$ & Comportamentos de uso e compra \\
\hline 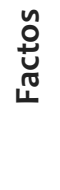 & $\begin{array}{l}\text { Idade, coortes etárias, género, } \\
\text { estado civil, ciclo de vida familiar, } \\
\text { rendimento, educação, ocupação, } \\
\text { classe social, geo-demográfico. }\end{array}$ & $\begin{array}{l}\text { Frequência de uso, situação/ocasião de } \\
\text { uso, lealdade face à marca, elementos } \\
\text { psicográficos e de estilo de vida } \\
\text { (interesses, opiniões, lazer). }\end{array}$ \\
\hline ○ & $\begin{array}{c}\text { Personalidade, estilos de vida e } \\
\text { valores socioculturais }\end{array}$ & $\begin{array}{l}\text { Atitudes e preferências relativas ao } \\
\text { produto }\end{array}$ \\
\hline ర్ & $\begin{array}{l}\text { Traços de personalidade, variáveis } \\
\text { psicográficas e de estilos de vida, } \\
\text { valores e sistema de crenças. }\end{array}$ & $\begin{array}{c}\text { Benefícios desejados, nível de } \\
\text { envolvimento, informação de } \\
\text { alternativas ao produto, lealdade de } \\
\text { marca. }\end{array}$ \\
\hline
\end{tabular}

Fonte: Adaptado de Schiffman, Kanuk e Wisenblit (2010).

Esta abordagem inicial permite que se estabeleça um primeiro quadro de referência para a diferenciação dos consumidores. No entanto, outros conceitos poderão ser explorados como a diferenciação por gerações. É através de Jaeger (1985) que surge a delimitação do conceito de geração. Pensa-se que este conceito geracional advém da tentativa de Comte (1998) referenciar um tempo quantitativo e objetivamente mensurável como critério para o processo linear (Feixa \& Leccardi, 2010). Segundo estes, o tempo de uma geração é pensado como o tempo médio de substituição de gerações, cerca de trinta anos, estando estes relacionados com a duração média de vida (cf. Comte, 1998).

A este conceito contrapõem-se uma outra abordagem, baseada na teoria de Jaeger (1985), que procura compreender a origem da homogeneidade das tradições intelectuais.

Para o investigador, não existe propriamente uma sucessão de gerações, através de um ritmo sequencial uniforme, mas estas provêm da qualidade dos vínculos que os indivíduos mantêm em conjunto (Feixa \& Leccardi, 2010).

De acordo com Jaeger (1985), o que define uma geração é a partilha de acontecimentos e experiências numa determinada temporalidade daí que as "impressões formativas recebidas 
num período de tempo relativamente curto durante a adolescência permanecem quase inalteráveis mesmo que expostas a fortes impressões de natureza oposta" (Jaeger, 1985: 276).

Estes dois enquadramentos permitiram a Mannheim ([1923]1952: 276-322), criador da abordagem contemporânea do conceito de geração, desenvolvido no ensaio "The Problem of Generations" de 1923, referenciar o período formativo que ocorre durante a juventude como plataforma para a formação de uma nova geração. Mais tarde, Feitosa e Ikeda (2010) suportado por estudos de outros autores, em investigações prévias, vêm distinguir geração a partir do ano correspondente ao nascimento apoiado no conceito de coorte. Desta forma, considera-se a existência de momentos, ou seja, um conjunto determinado de acontecimentos históricos, sociais ou culturais que promovem alterações na sociedade de forma significativa. Apesar desta consideração, a revisão de literatura feita por Feitosa e Ikeda (2010) concluiu que os conceitos de geração e coortes não apresentam uma sólida componente teórica por não existir consenso quanto à definição de conceitos, dimensão e data de início das coortes. A Tabela 2 permite analisar as diferenças preconizadas pelo autor entre coortes e gerações.

Tabela 2. Comparação entre gerações e coortes

\begin{tabular}{c|l|l}
\hline $\begin{array}{c}\text { Significado } \\
\text { da palavra }\end{array}$ & $\begin{array}{l}\text { Coortes } \\
\text { uma legião romana. }\end{array}$ & $\begin{array}{l}\text { Gerações } \\
\text { época, luação média da vida de um homem. }\end{array}$ \\
\hline $\begin{array}{c}\text { Diferenciador } \\
\text { entre grupos }\end{array}$ & $\begin{array}{l}\text { A existência de momentos de } \\
\text { definição, que caracterizem o o } \\
\text { paradigma vigente. }\end{array}$ & $\begin{array}{l}\text { O ano de nascimento dos } \\
\text { consumidores. }\end{array}$ \\
\hline $\begin{array}{c}\text { Início de um } \\
\text { grupo }\end{array}$ & $\begin{array}{l}\text { Período em que o consumidor se } \\
\text { torna adulto. }\end{array}$ & Ano em que o consumidor nasce. \\
\hline Tamanho & $\begin{array}{l}\text { Preferencialmente todas as coortes } \\
\text { são de tamanho homogéneo, mas } \\
\text { depende arbitrariedade do autor. }\end{array}$ & $\begin{array}{l}\text { O tamanho não é necessariamente } \\
\text { igual. Deve corresponder a uma fase } \\
\text { da vida. }\end{array}$ \\
\hline Precisão & $\begin{array}{l}\text { Menor, pois depende da identificação } \\
\text { de factos isolados que caracterizem } \\
\text { um momento de definição. }\end{array}$ & $\begin{array}{l}\text { Maior, pois depende da arbitrariedade } \\
\text { do pesquisador. }\end{array}$ \\
\hline Exemplos & $\begin{array}{l}\text { Coorte daqueles que vivenciaram a } \\
\text { Segunda Guerra Mundial. }\end{array}$ & $\begin{array}{l}\text { Geração de nascidos durante os anos } \\
80 .\end{array}$
\end{tabular}

Fonte: Adaptado de Feitosa e Ikeda (2010).

Para o desenvolvimento desta investigação considerou-se, enquanto coorte, a Geração Millennial. Esta designação, popularizada através da utilização em estudos académicos, de consultoras e agências de publicidade, não é consensual. Quatro fatores determinam as várias designações utilizadas:

a) Cronológico ou a sua posição na sucessão de gerações - Geração Y (Sheahan, 2005), Geração Millennial (Strauss \& Howe, 1991);

b) Dimensão demográfica - Echo Boomers;

c) Mudanças socioculturais e económicas - Geração Global, Geração Digital (Tapscott, 1998);

d) Comportamentais - Geração Me (Twenge, 2006).

A terminologia Millennial surge dirigido ao contexto norte-americano através de Strauss e Howe (1991). Os autores desenvolveram um tipo de caracterização psicográfica (Tabela 3) que será referência em estudos futuros. Considera-se que, para se compreender uma geração, 
devem ser entendidas as diferentes formas de educação obtidas em criança, quais os acontecimentos públicos presenciados na adolescência e que relevo social estes assumem na passagem para a vida adulta.

Tabela 3. Estados Unidos da América como uma sequência de Gerações

\begin{tabular}{c|c} 
Geração & Ano de Nascimento \\
\hline Missionária & $1860-1882$ \\
\hline Lost & $1883-1900$ \\
\hline Geração Gl & $1901-1924$ \\
\hline Silent Generation & $1925-1943$ \\
\hline Baby Boomer & $1944-1964$ \\
\hline 13a Geração ou Geração X & $1965-1981$ \\
\hline Geração Millennial & $1982-2005(?)$
\end{tabular}

Fonte: Adaptado de Feitosa e Ikeda (2010).

Howe e Strauss (2003) caracterizam a Geração Millennials com um elevado sentido de responsabilidade, civismo e cooperação, sendo que para Silva e Oliveira (2016) esta geração é responsável por mais de quarenta por cento da força de trabalho global, salientando ser a geração mais extensa e com maior poder de compra, para além de possuir um elevado conhecimento tecnológico.

\section{A Web enquanto suporte de informação e comunicação}

A reflexão que se pretende fazer remete para um novo espaço de comunicação, a internet. Este recente suporte de informação, que para todos os efeitos se traduz por um conjunto de redes interligadas e mais corretamente designadas por Interconnected Networks, não significa muito mais que um gigantesco número de computadores e utilizadores em rede. O seu enquadramento, promovendo a inexistência de barreiras físicas, a capacidade de descentralização e de massificação de mensagens, é a garantia de uma maior circulação de informação. A interatividade gerada por todos os intervenientes constitui-se como o elemento mais importante e, ao mesmo tempo, mais percetível de toda a dinâmica da internet. Ao adicionarmos a gratuitidade, normalmente existente, poderemos afirmar que estamos perante um suporte de informação de eleição.

Mesmo sabendo que a internet se pode tornar num veículo de informações inapropriadas, dado não existir controlo sobre os conteúdos (Brito \& Lencastre, 2000) parece-nos consensual que esta se tornou uma opção de comunicação por excelência.

No entanto, nem sempre foi assim. O percurso foi lento, sem que muitos de nós tenhamos dado conta das mudanças de paradigma ocorridas na última década. Um dos fatores que promoveu uma maior alteração foi o facto de os utilizadores deixarem de ser meros recetores de informação, tendo passado a ter um papel ativo na sua construção e difusão. Hoje, todos os utilizadores podem produzir os conteúdos informativos que desejem, garantindo ainda a sua publicação na rede sem que sejam necessários conhecimentos de programação. Está alterado o conceito de Web para Web 2.0. 
A Web 2.0 permite que, em algumas aplicações, os conteúdos possam integrar informação veiculada por outros utilizadores. Estes pesquisam, consultam e integram informação, assumindo um maior protagonismo na criação de conteúdos, ou seja, tornam-se simultaneamente produtores e consumidores (Costa et al., 2009).

De acordo com Reis (2000), esta "nova" Web apresenta como ponto forte o facto de a comunicação poder ser prontamente modificada, garantir interação e boa apresentação visual.

Esta enorme facilidade de produção e colocação de conteúdos online promoveu, de acordo com Simão (2006), um conjunto de alterações significativas. A atividade e a capacidade crítica por parte dos utilizadores aumentaram, e novas comunidades foram criadas com base em interesses ou temas comuns, tendo em conta a maior facilidade na publicação de conteúdos. Este crescimento tornou-se vital para a criação de um maior número de relações interpessoais que fortalecem o sentido da própria comunidade e a criação de um serviço com maior qualidade, através do aumento do número de pessoas envolvidas na produção de conteúdos para a Web. Um maior número de utilizadores gera uma maior atualização, confirmação e validação dos conteúdos.

Neste sentido, comparativamente com os tradicionais meios de comunicação, a Web possibilita quatro importantes princípios: maior informação e conhecimento, um novo canal de comunicação business to business (B2B) e business to consumer (B2C), a crescente criação de comunidades virtuais e a facilitação de transações empresariais.

A Web é hoje reconhecida como uma excelente plataforma comunicacional e é garantia de uma comunicação mais eficaz, face à possibilidade de conjugar texto, vídeo, som e imagem.

\section{A afirmação das redes sociais como elemento de interação social}

Para Carvalho (2008) a facilidade em publicar conteúdos e comentar posts faz com que as redes sociais (online) de desenvolvam, estimulando o processo de interação social e de aprendizagem. Este processo de interação e aprendizagem leva a uma maior facilidade na permuta de influências.

Segundo O'Connor (2001: 9), quanto maior for o risco percecionado pelo consumidor na aquisição do produto ou serviço, maior é a probabilidade que este tem de procurar a informação que considera credível. No turismo, dada a intangibilidade e perecibilidade das variáveis e o facto do produto ou serviço não poder ser avaliado, a procura de informação revela-se ainda superior.

Com o incremento tecnológico e a proliferação da Web, o acesso à informação e ao conhecimento tornou-se mais facilitado, mais abrangente e muito mais rápido. As redes socias transportam-se para a Web como uma forma de uma vivência social dentro desse mesmo espaço.

Para Recuero (2009), a principal função das redes sociais é a possibilidade de relação e sociabilização através de ferramentas mediadas por um suporte. Logo, essas ferramentas proporcionam que os utilizadores possam comunicar, interagir e construir informação, com outros parceiros de rede, deixando rastos que permitem a sua identificação e opinião.

Ainda, de acordo com Recuero (2009), as redes sociais dividem-se em dois tipos. Por um lado, as redes sociais propriamente ditas e, por outro, as redes sociais apropriadas. As primeiras são aquelas que suportam as próprias redes sociais dos utilizadores ou atores, são sites cujo foco principal está na exposição publica das redes conectadas aos atores, ou seja, 
cuja finalidade está relacionada à publicitação dessas redes e em que as mais comuns são o facebook e linkedin ao apresentarem perfis e espaços próprios dos seus criadores.

As redes sociais apropriadas são aquelas que, apesar de não terem sido criadas no sentido de se apresentarem enquanto espaço para a construção de perfis pessoais, são apropriadas pelos utilizadores ao criarem elementos de interesse comum, tais como o twitter, o instagram, ou mesmo os blogues.

Para além de nos referirmos a um ou outro tipo de rede social, podemos considerar que o interesse dos utilizadores incide no conceito de agregação de conteúdos, partilha de opiniões ou transferência de conhecimento, independentemente do que este mesmo conhecimento possa ser. Apesar de se poder afirmar que a ideia de relação social é independente do conteúdo (Recuero, 2009: 37), devemos considerar que o conteúdo de um conjunto de interações permite identificar o tipo de relação social existente entre os vários utilizadores.

As relações criadas através de suporte tecnológico apresentam vantagens quando comparadas com as pessoais. O distanciamento promovido pela tecnologia garante, caso $\mathrm{o}$ utilizador pretenda, o anonimato. A relação que se estabelece entre o corpo físico e a personalidade do utilizador pode não ser dada a conhecer, contribuindo para uma maior facilidade no começo e no términus das relações. Questões como raça, orientação sexual, idade, enquadramento social ou limitações físicas podem não ser dadas a conhecer, garantindo uma total liberdade de movimentos na Web.

Os laços sociais, criados através das redes sociais, são a verdadeira razão de conexão entre os utilizadores ou atores envolvidos no ato de comunicação, ou seja, são a verdadeira razão da congregação das relações estabelecidas entre os utilizadores das redes sociais.

Podemos afirmar que laços são formas mais institucionalizadas de conexão entre atores, constituídas no tempo e através da interação social (Recuero, 2009) e que Wellman (2001: 227) define como algo que "consiste em uma ou mais relações específicas, tais como proximidade, contato frequente, fluxos de informação, conflito ou suporte emocional. A interconexão destes laços canaliza recursos para localizações específicas na estrutura dos sistemas sociais. Os padrões destas relações - a estrutura da rede social - organiza os sistemas de troca, controle, dependência, cooperação e conflito".

De acordo com a PhocusWright, uma empresa especializada em tecnologia de informação, citada pela consultora em marketing digital, Phocuswright (2016), o networking social é uma das ferramentas mais poderosas para o turismo.

Este permite-nos reconhecer que a opinião de todos aqueles que conhecemos, e dos quais temos uma ideia formada, se torna importante para que possamos validar ou esclarecer dúvidas. Numa vertente de turismo, este conceito ganha uma importância acrescida face à intangibilidade do produto/serviço.

Neste sentido, as opiniões que possamos considerar isentas ganham um papel importante na nossa tomada de decisão. É por esta razão que os sites referentes a destinos ou recursos turísticos apresentam uma significativa representatividade na tomada de decisão do turista.

Atualmente, com a proliferação de utilizadores de redes sociais, tornou-se habitual a colocação de fotografias de paisagens, comida, marcas, locais, etc., acrescida de comentários que permitem identificar a opinião do autor. Posteriormente, os comentários fundamentam, ou não, essas mesmas opiniões. Desta forma, pode-se referir que as redes sociais permitem partilhar as experiências vividas com o mundo. 


\section{O desejo dos Millennials}

A proximidade à tecnologia é um dado adquirido por parte desta geração. A tecnologia é utilizada como ferramenta de comunicação bidirecional. Por um lado, perspetivando a facilidade de passar determinada mensagem e, por outro, como facilitador de acesso à informação quer esta seja formal ou informal. De acordo com a Salesforce Desk.com (2015), os Millennials recorrem à tecnologia quando necessitam de informação sobre uma qualquer organização. Um quarto dos Millennials espera obter resposta de uma empresa no período máximo de dez minutos após o envio de uma mensagem através das redes sociais.

A fidelização é também um fator relevante para a escolha do consumidor. Segundo o estudo realizado pela Salesforce Desk.com, 22\% dos entrevistados da faixa etária visada já desistiram de uma compra por terem sido mal atendidos ou ignorados pelo serviço ao cliente.

Para além destas evidências, a necessidade de percorrer, num mesmo contacto, várias pessoas sem uma resposta concreta e a falta de educação dos colaboradores da organização são duas outras experiências negativas que levam à rejeição de uma marca/organização.

Como já referimos, são as redes sociais, no que à comunicação se refere, o suporte preferencial da Geração Millennials. Cerca de $81 \%$ dos inquiridos preferem as redes sociais a suportes como o telefone, os Websites ou os chats online. Nas redes sociais, o facebook é a opção mais comum, cerca de $78 \%$ dos entrevistados avaliaram-no como a ferramenta mais eficiente para o serviço ao cliente. O Twitter é a segunda opção mais procurada, com $43 \%$ dos inquiridos a validar esta opção.

Sobre a forma como gerem a utilização da rede social, 55\% dos Millennials referem que compartilhariam com amigos e familiares as boas experiências de interação com marcas e serviços e $37 \%$ compartilhariam no seu perfil qualquer tipo de atendimento que considerassem positivo.

Mas, o que valoriza verdadeiramente a Geração Millennials? De acordo com um estudo realizado nos EUA, pela plataforma online de gestão de eventos Eventbrite ${ }^{2}$ (2015), esta geração valoriza essencialmente o conjunto de experiências vividas e o tempo e dinheiro que gastam com eles próprios. Não são os bens materiais ou o estatuto da vida profissional que os faz felizes, mas sim a criação, partilha e captura de memórias adquiridas nas experiências. 0 estudo concluiu que $78 \%$ dos jovens escolheriam gastar dinheiro com experiências em vez de objetos materiais. Cerca de 55\% afirmaram que estão dispostos a gastar o dinheiro em experiências e que $82 \%$ dos inquiridos frequentaram mais experiências ao vivo em festas, espetáculos, festivais e desporto do que gerações mais velhas (70\%).

Cerca de $77 \%$ dos inquiridos referem que as suas melhores recordações foram obtidas em experiências e eventos ao vivo. Por outro lado, $69 \%$ acreditam que essa forma de estar os mantém mais ligados às pessoas, à comunidade e ao mundo. $O$ estudo refere ainda que os inquiridos preferem experimentar e viver a vida através de experiências do que investir o dinheiro em bens materiais. Os Millennials, ao darem uma elevada importância à informação e ao conhecimento, bem como à partilha destes, tornam constante o uso das redes sociais.

A pesquisa refere ainda que cerca de $69 \%$ têm $\mathrm{FOMO}^{3}$, medo de perder uma ótima experiência se deixar de estar presente num determinado evento. Os inquiridos consideram que cada evento é único e irrepetível. Para a geração, o FOMO não é apenas um fenómeno cultural, é visto como uma epidemia.

\footnotetext{
${ }^{1}$ http://www.salesforce.com/desk/overview/.

2 https://www.eventbrite.pt/.

3 FOMO é o acrónimo de fear of missing out.
} 
Após esta análise, importa referenciar um outro estudo, encomendado pela Asociación de Agencias de Viajes del Pacífico y Asia (PATA) e realizado pela consultora Gen C Traveller (2015), no qual foram inquiridos cerca de 3000 turistas asiáticos, com idades compreendidas entre os 15 e os 29 anos e, por isso, referenciados como Geração Millennials.

De acordo com Porras (2015), citando esse mesmo estudo, os jovens asiáticos, enquanto turistas, são grandemente responsáveis pelo incremento do turismo na Europa e são um tipo de turista permanentemente conectado e com enorme interesse em conhecer outras culturas.

De acordo com a consultora, os dados recolhidos apontam para a importância de demonstrar interesse e respeito pela cultura dos turistas. Destaca-se, também, a importância da existência de informação sobre os recursos turísticos, desejavelmente veiculada em formato mobile (telemóvel ou tablet), que são hoje as ferramentas de suporte Web mais utilizadas. Segundo o mesmo estudo, a principal motivação da Geração Millennials para fazer turismo, fora do seu país, é o desejo de conhecer novos lugares, ter novas experiências para partilhar com amigos nas redes sociais, seguir sugestões de familiares e amigos, aproveitar as ofertas especiais de viagens e alojamentos.

Para a consultora, esta é uma população permanentemente ligada à internet e, por essa razão, é essencial a oferta tecnológica por parte dos agentes de turismo. $O$ inquérito revelou que 70\% dos turistas asiáticos realizam as suas reservas via online. Quando questionados sobre as aplicações (apps) mais utilizadas, os inquiridos revelam que são todas aquelas que ofereçam tradução de idiomas, localização rápida de transportes e alojamento local. A opção sobre o alojamento recai normalmente em hotéis de 1 a 3 estrelas.

\section{O recurso turístico em rede: Espaço para as redes sociais}

Desde os primórdios que o ser humano sente necessidade de se deslocar entre locais, independentemente da razão que possamos encontrar para que o faça.

Para a OMT (1995: 12), o turismo compreende todas as atividades das pessoas que viajam e permanecem em locais fora do seu ambiente habitual, considerando como ambiente habitual, uma determinada área em que a pessoa fixou residência e outros locais que frequentemente visita, num período não superior a um ano, por motivos de lazer, negócios, ou outros propósitos.

Sabemos que os motivos que levam as pessoas a viajar estão diretamente relacionados com as características dos destinos e dos seus recursos. Segundo Cunha (2009), estes podem classificar-se em: turismo de recreio, repouso, cultural, étnico, natureza, negócios e desportivo. Apesar de distintos nas suas características, o que os permite diferenciarem-se, nada impede que estes coexistam no mesmo espaço.

Ao serem abordadas as características do destino, os recursos existentes devem ser considerados. O turismo desenvolve-se nos espaços que apresentam uma série de atratividades que geram procura turística (Barbosa, 2009: 6). Segundo Domingues (1997: 256), o recurso turístico é todo o tipo de atrativo, natural ou artificial, que exerce um apelo suficientemente forte para promover a deslocação de pessoas com o objetivo de ser apreciado, visitado, utilizado ou simplesmente fruído. Esta atratividade, que remete o turista para uma determinada área (local ou região), é o resultado da atividade humana, e resulta na capacidade de atrair todos os que residam fora da região e pretendam pernoitar. Neste sentido, quanto melhor se identificar o conjunto de recursos turísticos de uma região, mais facilitada será a tarefa de determinar o seu potencial turístico e, obviamente, de estruturar e organizar o seu desenvolvimento. 
Para Machín (1997), singularidade, atratividade e estado de conservação dos recursos turísticos, bem como a sua localização e facilidade de acesso, determinam a possibilidade de exploração e de atração de um determinado tipo de visitantes. Estes elementos tornam-se fundamentais considerando que os Millennials possuem um elevado conjuntos de expectativas, comportamentos e preferências em relação a tudo o que se relaciona com as suas experiências de viagens.

No que aos recursos diz respeito, o fácil e correto acesso à informação e a garantia de que as expetativas não serão defraudadas durante a sua experiência, são fundamentais para os Millennials.

A existência de conexão wi-fi na chegada ao hotel ou a qualquer outro recurso turístico, permitindo antecipar ou confirmar informação, identificar elementos ou partilhar as suas fantásticas experiências com amigos em tempo real, faz certamente a diferença.

Esta geração é aquela que, de acordo com a EnterTravel ${ }^{4}$ (2014), divide os seus gastos anuais entre viagens de lazer e negócios, exigindo uma permanentemente instantaneidade e precisão a partir do tablet ou telemóvel.

De acordo com os mesmos autores, os Millennials exploram os destinos e os seus recursos, ansiando por aventuras e experiências únicas e autênticas e valorizam experiências distintas e exclusivas que possam ser exibidas nas redes sociais. Para além da exclusividade da experiência, esperam encontrar conteúdos personalizados, aquando da compra de bilhetes de avião, reserva de hotéis ou pesquisa de restaurantes. Estes são aspetos relevantes de adequação dos recursos turísticos que não deve ser apenas à Geração Millennial como também a gerações vindouras, garantindo a satisfação e a respetiva fidelização.

Numa geração tech, comunicar através das redes sociais, mantendo o contato com amigos e familiares, através da tecnologia móvel, são aspetos de elevada importância. A tecnologia garante uma inegável sensação de poder, proporcionando o acesso a grandes quantidades de informação em qualquer momento. A comparação de preços, as sugestões de "amigos" em redes sociais ou blogues, durante a viagem, ou as compras online são valorizadas pelo conforto e segurança que a conectividade constante possibilita.

Para a EnterTravel (2014), torna-se fundamental compreender as semelhanças e as diferenças entre os grupos de consumidores. A informação permitirá que as organizações inovem continuadamente e possam fornecer ferramentas e tecnologias que respondam às necessidades de todas as gerações.

\section{Metodologia}

Após a revisão bibliográfica considerada mais relevante, refletiu-se sobre a forma como se poderia responder à questão primária da investigação, questionando os vários condicionalismos existentes para a definição da população e respetiva amostra de estudo.

A população a estudar está definida pelo enquadramento da investigação e advém da literatura estudada, pessoas de ambos os sexos nascidas entre 1982 - 2005 de acordo com Feitosa e Ikeda (2010: 5).

Neste sentido, partindo para uma avaliação quantitativa e recorrendo ao inquérito por questionário, foi utilizado o método não probabilístico e escolhida uma amostra por conveniência.

\footnotetext{
${ }^{4}$ https://entertravel.wordpress.com/
} 
Foram inquiridos alunos do ensino profissional de uma escola da zona de Lisboa, previamente selecionada através do método aleatório, tendo como propósito a base de análise da Geração Millennials, (as escolas profissionais da zona de Lisboa foram numeradas por ordem alfabética tendo sido utilizada a função aleatória da ferramenta excel da Microsoft). Sabia-se que todos os alunos inquiridos correspondiam à faixa etária que se decidiu investigar.

O questionário, realizado através da ferramenta Google Forms e enviado para os respondentes através do facebook, foi previamente testado e validado, no que se refere à sua interpretação, por um grupo de dez alunos, similar à amostra estudada e pertencente ao mesmo estabelecimento de ensino (ver Anexo 1). O tratamento estatístico foi efetuado através dos elementos extraídos da própria ferramenta Google Forms, tendo posteriormente sido trabalhados em excel.

\section{Análise de resultados}

Dos 104 alunos referenciados nas 5 turmas obtiveram-se 68 respostas, perfazendo cerca de $65 \%$ de respondentes. Das 68 respostas, 40 (58,8\%) corresponderam ao género feminino e 28 $(41,2 \%)$ ao género masculino.

Figura 1. Género dos inquiridos

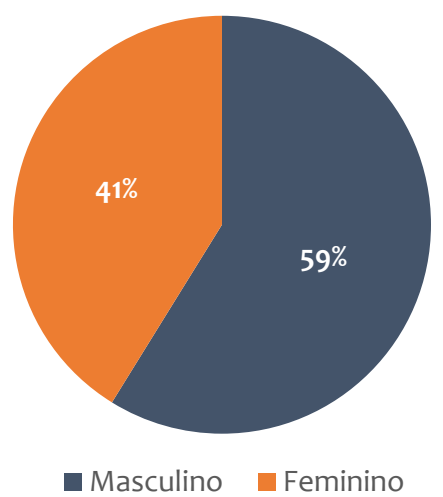

Dos inquiridos, constata-se que todos referem uma utilização frequente $(35,3 \%)$ ou muito frequente da internet $(64,7 \%)$, corroborando os valores da bibliografia apresentados.

Figura 2. Como considera a utilização que faz da internet?

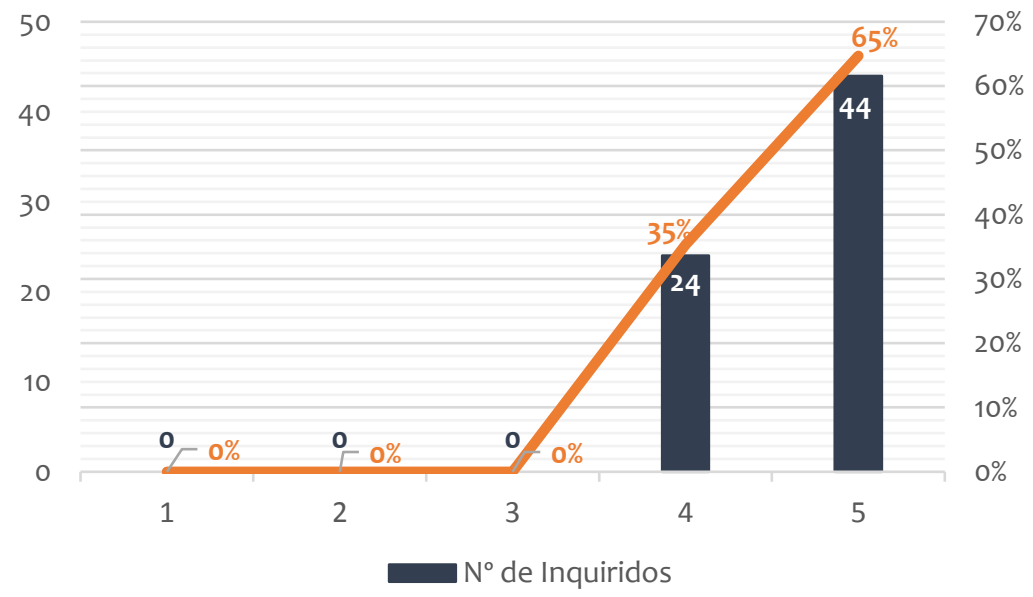


Quando questionados sobre o gosto por viajar, 66,2\% revelam que gostam muito de viajar. No entanto, 7 inquiridos (10,3\%) referem ser indiferente. Considera-se que o nível socioeconómico da amostra estudada possa condicionar o resultado desta questão, bem como o facto de no questionário não estar mencionado o significado de viajar.

Figura 3. Gosta de viajar?

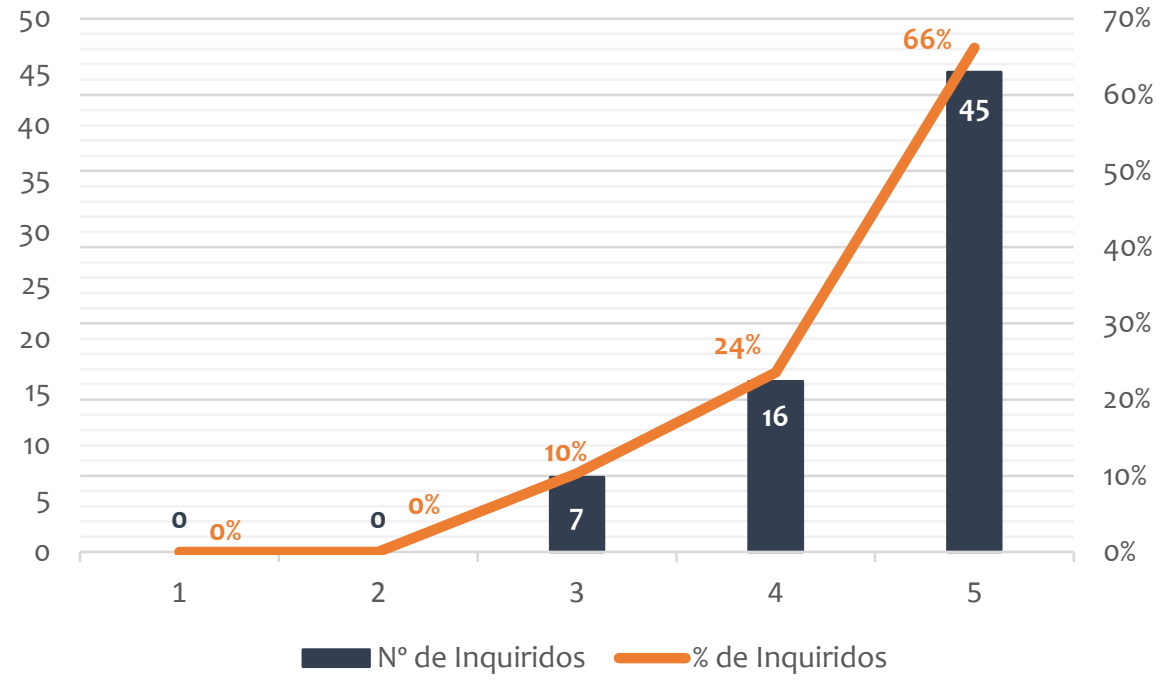

Os resultados obtidos na resposta à questão seguinte podem ilustrar o anteriormente referido. Quando questionados sobre o hábito de viajar, 13 inquiridos (19,1\%) referem que pouco ou nada viajam. No entanto, apenas $26(38,3 \%)$ referem viajar bastante ou muito. Estes dados, por comparação com os dados lançados por Porras (2015), deixam a Geração Millennials portuguesa a uma invejável distância dos Millennials asiáticos.

Figura 4. Costuma viajar?

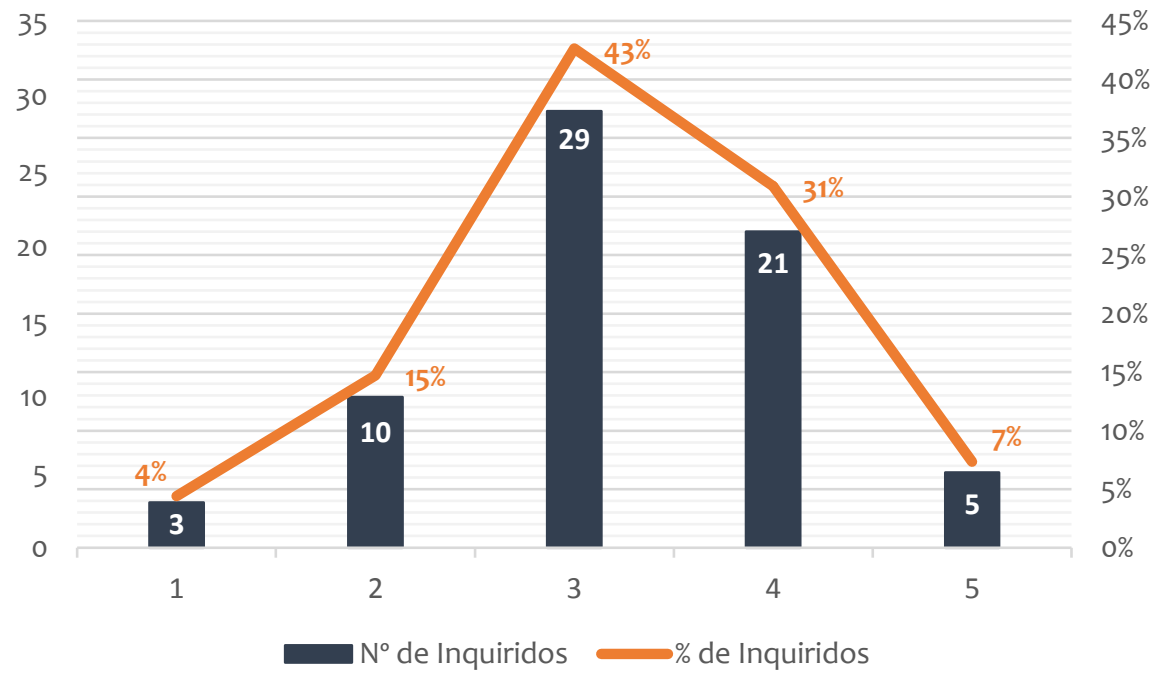

No entanto, pode-se afirmar que os Millennials são efetivamente uma geração de internautas. Mesmo numa ótica de viagem, 65 inquiridos (94\%) referem que o acesso à internet é significativamente importante, não dispensando, por esse facto, a sua presença. Como foi 
observado na Figura 2, e se pode verificar através da Figura 5, uma elevada percentagem de inquiridos destaca a importância do recurso permanente à internet, validando a primeira hipótese (H1).

Figura 5. Quando viaja, torna-se determinante ter acesso à internet?

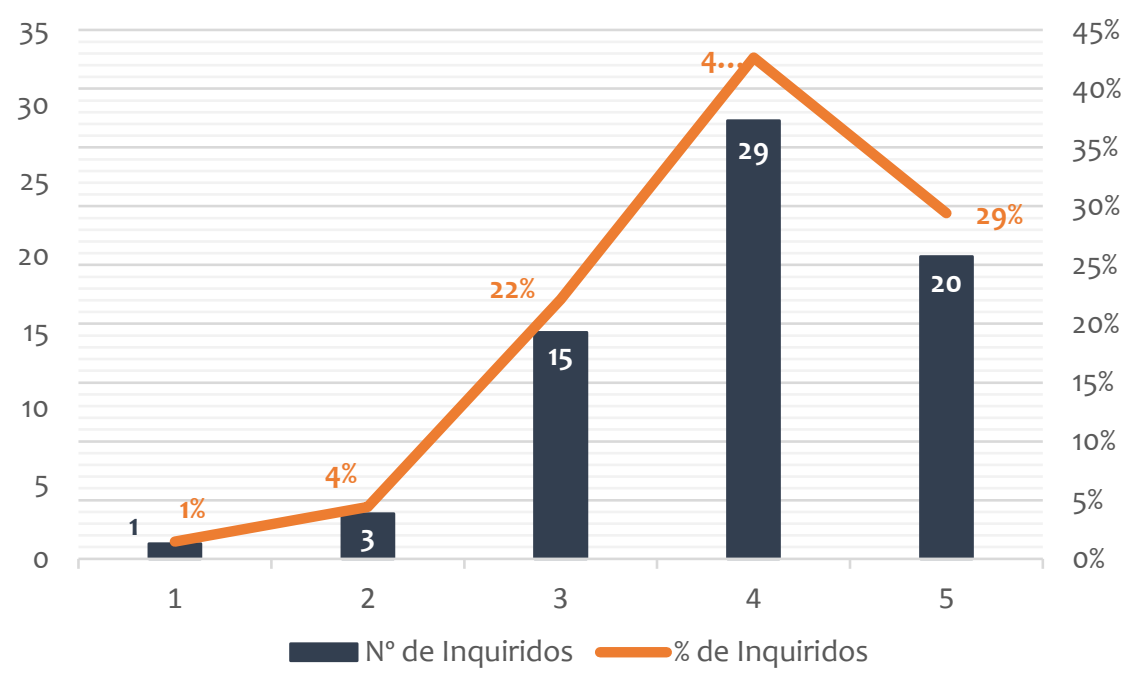

Inegável é a relação dos Millennials com as experiências. Apenas 1 (1,5\%) dos inquiridos refere que não é importante que a sua vigem tenha uma forte componente de novas experiências. Mais uma vez, este índice acompanha os resultados veiculados por Porras (2015). Para 98,5\% dos inquiridos, a experiência é importante no decurso da sua viagem. Em suma, as viagens têm de apresentar uma forte componente experiencial, permitindo confirmar a hipótese $2(\mathrm{H} 2)$.

Figura 6. Quando viaja é importante que a viagem tenha uma forte componente de novas experiências?

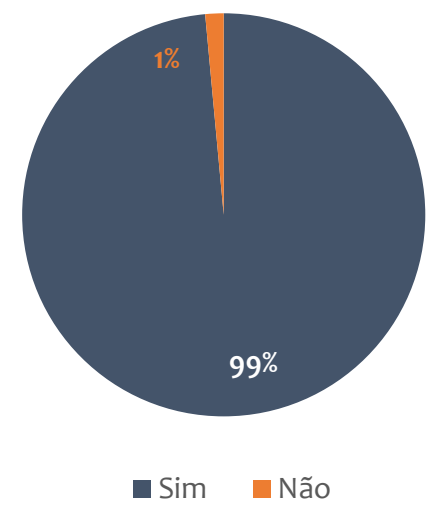

Se foi observado um forte pendor na utilização da internet por parte dos Millennials portugueses estudados, o mesmo não se pode dizer no que se refere à partilha de elementos da viagem nas redes sociais. Apenas $39(57,4 \%)$ inquiridos consideram fundamental essa mesma partilha. Mesmo assim, estes dados permitem validar a hipótese $3\left(\mathrm{H}_{3}\right)$. 
Figura 7. Quando viaja é fundamental partilhar elementos da viagem nas redes sociais?

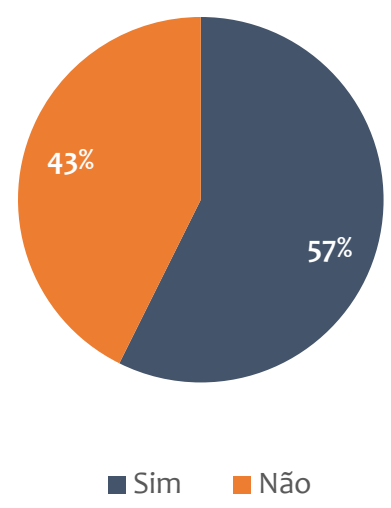

No entanto, apesar de uma elevada percentagem não partilhar a informação das suas viagens, uma larga maioria, 56 inquiridos (82,4\%), costuma recorrer à informação da internet ou das redes sociais para identificar e/ou explorar novos recursos turísticos. Estes dados permitem concluir que a utilização da Web para identificar/explorar recursos é determinante durante a viagem, confirmando a hipótese $4\left(\mathrm{H}_{4}\right)$. Considera-se ainda oportuno identificar que o género feminino apresenta maior apetência para recorrer à Web na identificação e/ou exploração dos recursos turísticos, como se observa na Figura 8.

Figura 8. Durante a viagem costuma recorrer à informação da internet/redes sociais para identificar/explorar novos recursos turísticos?

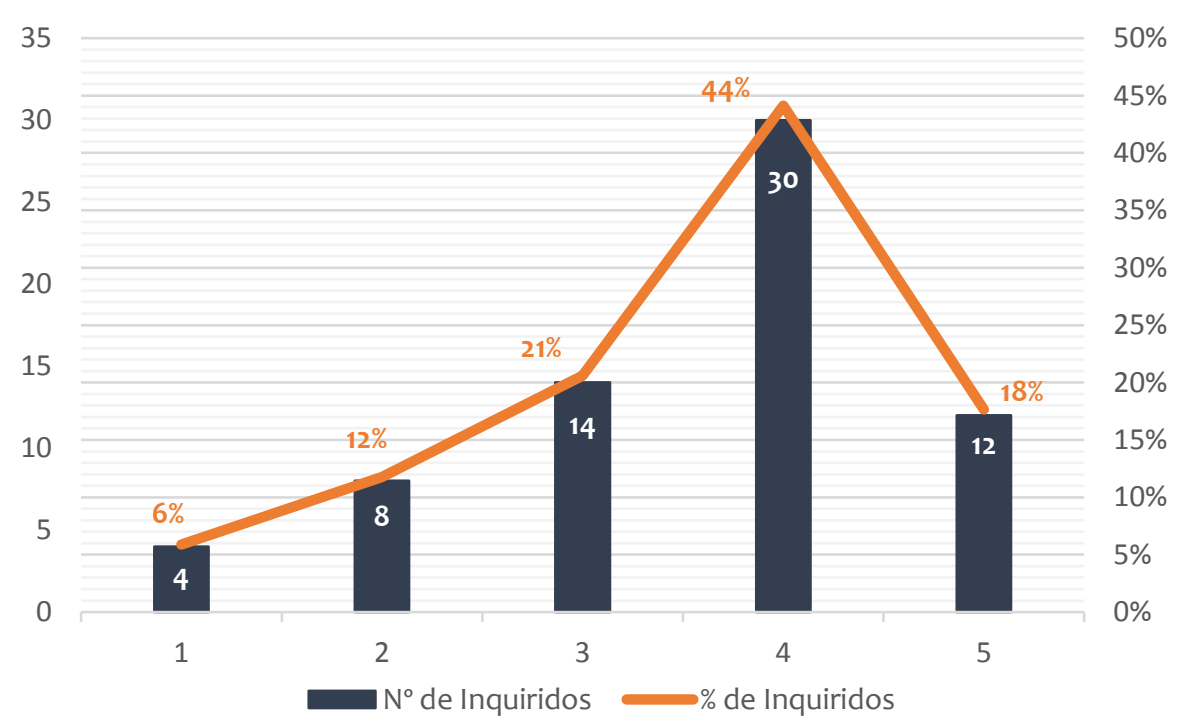

Tinha sido já concluído a importância da experiência durante a viagem para os Millennials portugueses. No entanto, é de referir que essa análise se acentua quando se constata que 63 dos inquiridos (93,6\%) referem que o facto de poderem desfrutar de novas experiências é determinante para a marcação da viagem.

Constata-se que conhecer novos lugares e ter novas experiencias é um fator determinante para que a viagem aconteça, permitindo validar a hipótese $5\left(\mathrm{H}_{5}\right)$, como se pode verificar na Figura 9. 
Figura 9. Desfrutar de novas experiências é determinante para a marcação da viagem?

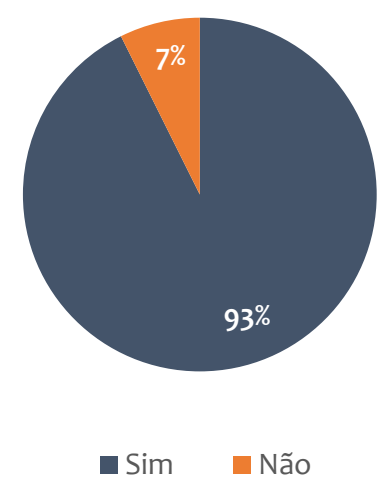

A relação dos Millennials com a internet e com as redes sociais parece ser perfeitamente evidente. No entanto, parece fundamental associar o papel determinante, na opinião dos inquiridos, para a comunicação dos recursos turísticos. De facto 59 (86,8\%) dos Millennials avaliados manifestam que a internet é determinante para a escolha de um determinado recurso turístico, antes ou durante a viagem.

Desta forma, sendo percetível que a internet foi determinante na escolha do recurso turístico que se pretendia visitar, considera-se validada a hipótese 6 (H6), como é observável na Figura 10.

Figura 10. A internet é determinante para a escolha de um determinado recurso turístico antes ou durante a viagem?

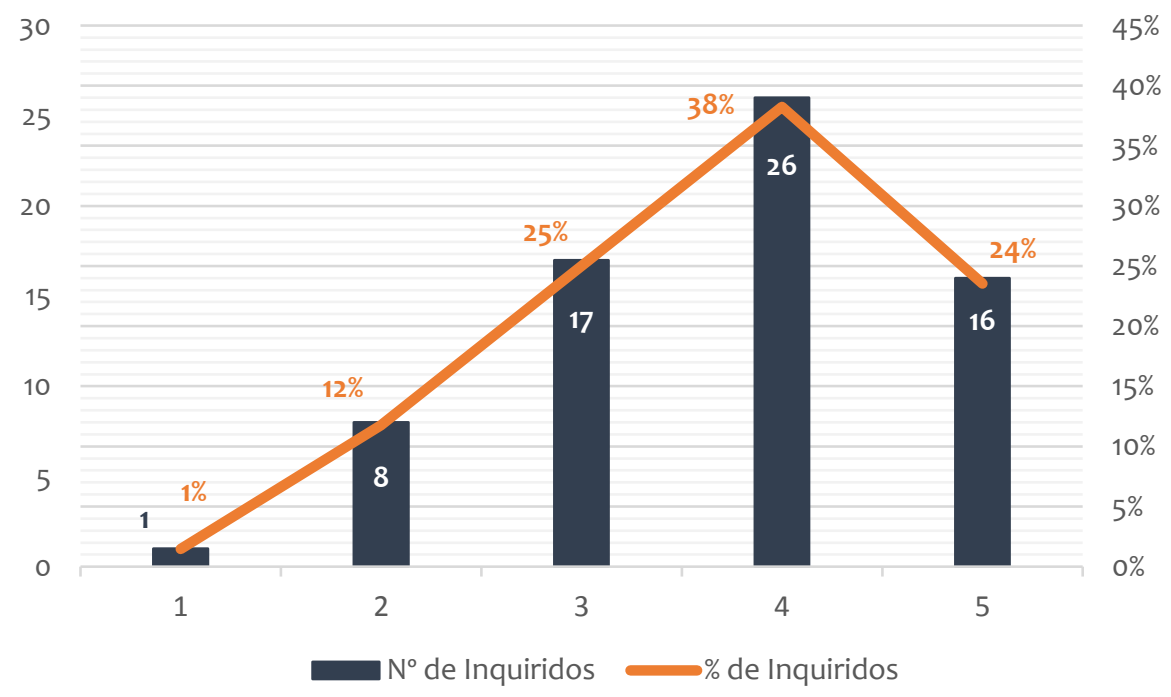

Por último, merece destaque, pela importância que pode apresentar para uma estratégia de comunicação, a análise por género das variáveis anteriormente analisadas. Como poderemos observar, não é significativa a diferença de opinião entre o género masculino e o feminino nas seis questões abordadas. No entanto, merece destaque, por ser a categoria que apresenta uma maior diferença, o facto de o género feminino apresentar uma maior apetência para recorrer à informação da internet ou das redes sociais quando identifica e/ou explora novos recursos turísticos. 
Sem que se possa considerar determinante, a comunicação dos recursos poderá ter um cariz diferente, face aos públicos a quem se dirige. Neste caso, identificou-se uma ligeira diferença na tendência de uso da internet ou das redes sociais, sendo o género feminino o maior utilizador.

Figura 11. Variação média entre géneros das variáveis investigadas

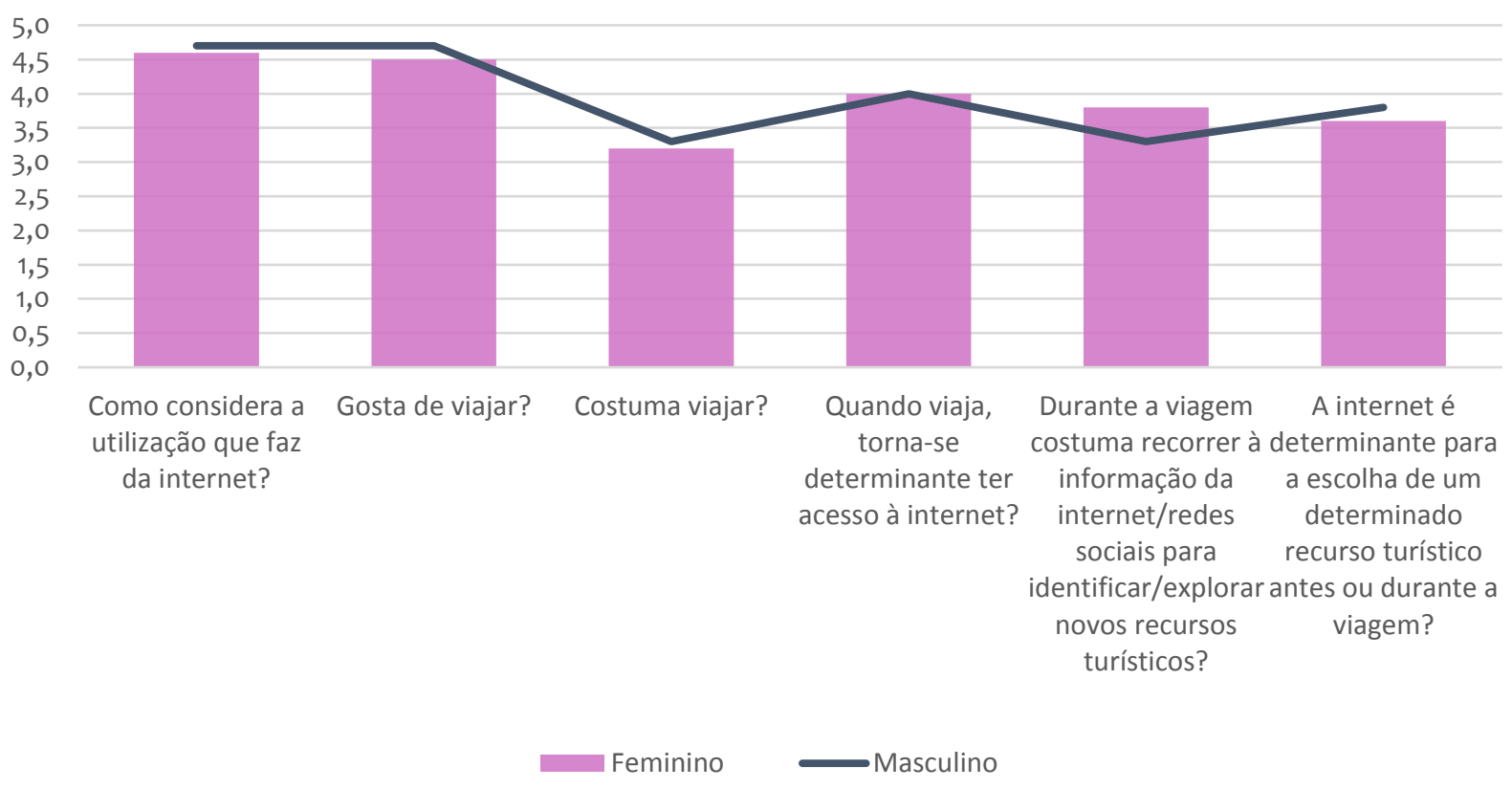

\section{Conclusões}

Após a conclusão desta investigação, confirmam-se um conjunto de inputs referenciados pela revisão bibliográfica, apesar de parecer pertinente salientar que a limitação da amostra não permite extrapolar os dados obtidos aos restantes Millennials portugueses.

Promovendo a relação entre a bibliografia estudada e os dados recolhidos verifica-se que a internet se tornou uma opção de comunicação por excelência, nomeadamente as redes sociais. Salienta-se, por exemplo a referência de Carvalho (2008: 8) quando este afirma que a facilidade em publicar conteúdos e em comentar os posts fez com que as redes sociais online se desenvolvessem.

De facto, constata-se nos dados obtidos uma forte utilização da internet e das redes sociais pelos Millennials tendo, neste caso, como limite a amostra estudada. Ainda, como relatado pela Eventbrite (2015), a Geração Millennials também valoriza, essencialmente, o conjunto de experiências vividas.

Os dados recolhidos permitem ainda identificar que as melhores recordações foram obtidas em experiências e eventos ao vivo e que o desejo de conhecer novos lugares, ter novas experiências e compartilhá-las com amigos nas redes sociais é determinante no modo de vida dos Millennials. Estes vivem a Web, as experiências e utilizam a internet como fonte de conhecimento para as suas viagens e, em particular, para a identificação dos recursos turísticos de determinado destino.

Conclui-se que a amostra de Millennials portugueses estudada em nada não se diferencia do restante padrão, dado a sua semelhança ao que é globalmente referenciado na literatura internacional. 
Para finalizar, não podemos deixar de salvaguardar, enquanto limitação da investigação, o reduzido número da amostra, bem como o facto de os inquiridos, apesar de estarem na idade consignada pela literatura e de pertencerem à Geração Millennials, referirem o facto de não viajarem muito. Considerando que esta investigação pode ser considerada relevante no panorama da geração em questão, sugerem-se duas recomendações para futuras investigações. A análise socioeconómica dos respondentes, considerando que esta pode ser determinante para o hábito de viajar e para as suas experiências enquanto turistas e uma generalização da amostra, incluindo estudantes com outros níveis de escolaridade.

Por último, salienta-se que já no final desta investigação, foi dado destaque a uma notícia, no portal da revista Marketeer (2016) que, pela sua singularidade e oportunidade, merece destaque:

\begin{abstract}
Nascidos depois de 1997, os Plurals formam a geração mais etnicamente diversa da história dos Estados Unidos da América, são nativos digitais e utilizadores activos das tecnologias mobile do ponto de vista do consumo. É assim que a Turner, empresa da Time Warner responsável pelos conteúdos de anunciantes em canais como CNN e NBA TV, descreve a geração pós-Millennials. A Turner acrescenta que os Plurals são omnívoros do entretenimento, o que significa que utilizam um leque alargado de canais e operadores para aceder aos conteúdos televisivos e digitais a que querem assistir. Uma das principais diferenças entre os Plurals e os Millennials está na forma como as novas tecnologias chegaram a cada uma destas gerações. Ao passo que os Millennials tiveram de aprender a lidar com uma fonte quase inacabável de inovações e hipóteses, os Plurals esperam e exigem que exista escolha.
\end{abstract}

De facto, os Plurals, que já nasceram no meio da tecnologia digital e da tecnologia mobile, usam um alargado número de canais e operadores, no acesso aos conteúdos televisivos e digitais, escolhendo e controlando o tipo de conteúdos que querem ver.

Contrariamente aos Millennials que tiveram de aprender a lidar com uma quantidade infindável de inovações tecnológicas, os Plurals exigem que a tecnologia esteja disponível e garanta uma elevada abrangência de utilização.

\title{
Referências
}

Barbosa, A. J. (2009). Reflexões sobre o conceito de produto turístico e sua gestão integrada. Desafios para o produto turístico "Santo Antão". Revista de Investigación en Turismo e Desarrollo Local, 2(6), $1-14$.

Brito, C. \& Lencastre, P. (2000). Os horizontes do marketing. Lisboa: Editorial Verbo.

Buhalis, D. (2000). Marketing the competitive destination of the future. Tourism Management, 21(1), 97116. doi: 10.1016/S0261-5177(99)00095-3.

Carvalho, A. A. (2008). Manual de ferramentas da Web 2.0 para professores. Lisboa: Ministério da Educação.

Comte, A. ([1830-1842]1998). Cours de philosophie positive (vols. 1-2). Paris: Hermann.

Costa, J., Ferreira, J. C., Domingues, L., Tavares, T., Diegues, V., \& Coutinho, C. (2009). Conhecer e utilizar a Web 2.0: Um estudo com professores do $2 .^{\circ}, 3 .^{\circ}$ ciclos e secundário. Actas do $X$ Congresso Internacional Galego-Português de Psicopedagogia, (pp. 5614-5630). Braga.

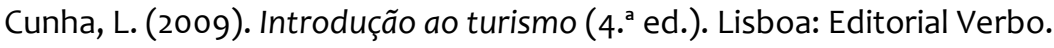

Domingues, C. M. (1997). Prontuário turístico. Lisboa: Instituto Nacional de Formação Turística.

Doolin, B., Bourgess, L. \& Cooper, J. (2002). Evaluating the use of the web for tourism marketing: A case study from New Zealand. Tourism Management 23(5), 557-561. doi: 10.1016/S0261-5177(02)00014-6

EnterTravel. (2014). Três tendências para compreender o turista Millennial (ou da geração Y). Entertravel. Disponível em https://entertravel.wordpress.com/2014/06/20/3-tendencias-para-compreender-oturista-millennial-ou-da-geracao-y/ 
Feitosa, W. R. \& Ikeda, A. A. (2010). A segmentação de mercado por meio de coortes sob a ótica de pesquisadores e profissionais de marketing. In Atas da XIII Semead, Seminários em Administração (pp. 1-16). São Paulo: Universidade de São Paulo.

Feixa, C. \& Leccardi, C. (2010). O conceito de geração nas teorias sobre juventude. Revista Sociedade e Estado, 25(8), 185-204.

Howe, N. \& Strauss , W. (2003). Millennials go to college: Strategies for a new generation on campus: Recruiting and admissions, campus life, and the classroom. Washington: American Association of Collegiate Registrars and Admissions Officers.

Jaeger, H. (1985). Generations in history: Reflections on a controversial concept. History and Theory, 24(3), 273-292.

Kim, H. \& Fesenmaie, D. R. (2008). Persuasive design of destination web sites: An analysis of first impression. Journal of Travel Research, 47 (1), 3-13. doi: 10.1177/0047287507312405.

Kotler, P. (1980). Marketing management: Analysis, planning, implemetation, and control. New Jersey: Prentice-Hall.

Machín, C. A. (1997). Marketing y turismo. Madrid: Gestión Turística.

Mannheim, K. ([1923] 1952). The problem of generation. In K. Mannheim, Essays on the sociology of knowledge (pp. 276-322). London: Routledge \& Kegan Paul.

Marketeer (2016, 18 janeiro). Plurals são a nova geração? Revista Marketeer. Disponível em http://marketeer.pt/2016/01/18/plurals-sao-a-nova-geracao/

O'Connor, P. (2001). Distribuição da informação eletrônica em turismo e hotelaria. Porto Alegre: Bookman.

Organização Mundial de Turismo (1995). Concepts, definitions and classifications for tourism statistics. Madrid: World Tourism Organization.

Organização Mundial de Turismo (2015). Tourism barometer. Disponível em http://tourlib.net/wto/UNWTO_Barometer_2015_06.pdf.

Park, Y. A. \& Gretzel, U. (2007). Success factors for destination marketing web sites: A qualitative metaanalysis. Journal of Travel Research, 46(1), 46-63. doi: 10.1177/0047287507302381

Phocuswright (2016, 4 de janeiro). Traveler technology survey 2010: Social networks. Disponível em http://www.phocuswright.com/.

Porras, C. (2015). Millennials orientales, el gran reto del sector. Hosteltur. Disponível em https://www.hosteltur.com/110099_millenniales-orientales-gran-reto-destinos-turisticos.html.

Recuero, R. (2009). Redes sociais na Internet. Porto Alegre: Editora Sulina.

Reis, J. L. (2000). O Marketing personalizado e as tecnologias de informação. Lisboa: Edições Centro Atlântico.

Schiffman, L. G., Kanuk, L. L. \& Wisenblit, J. (2010) Consumer behaviour. (10th ed.). New Jersey: Pearson and Prentice Hall.

Sheahan, P. (2005). Generation Y. Prahran: Hardie Grant Books.

Silva, S. C. \& Oliveira, R. (2016, 16 de janeiro). Os Millennials merecem a atenção do marketing. Disponível em http://www.hipersuper.pt/2013/01/04/os-millennials-merecem-a-atencao-do-marketing-porsusana-costa-e-silva-e-ruben-oliveira-catolica-porto/.

Simão, J. (2006). Relação entre os blogs e webjornalismo. Revista Prisma, 3, 148-164.

Solomon, M. R. (2006). Consumer behaviour: A European perspective. New Jersey: Financial Times/Prentice Hall.

Strauss, W. \& Howe, N. (1991). Generations: The history of America's future, 1584 to 2069. New York: Harper Collins.

Tadeu, N. (2015, 25 de fevereiro). Turismo em Portugal - setor em mudança e crescimento. Disponível em http://www.jornaleconomico.sapo.pt/noticias/turismo-em-portugal-setor-em-mudanca-ecrescimento-parte-1-11966.

Tapscott, D. (1998). Growing up digital. The rise of the net generation. New York: McGraw Hill

Twenge, J. M. (2006). Generation me: Why today's young americans are more confident, assertive, entitled - and more miserable than ever before. New York: Free Press.

Wellman, B. (2001). Physical place and cyberplace: The rise of personalized networking. The International Journal of Urban and Regional Research, 25(2), 227-252. doi: 10.1111/1468-2427.00309

Pedro Alves Trindade é doutorando em Turismo no Instituto de Geografia e Ordenamento do Território. É licenciado em Relações Públicas e Publicidade, pós-graduado em Comunicação de Marketing e mestre em Comunicação Integrada. Após uma longa experiência na Indústria Farmacêutica, integra um projeto de consultoria em Marketing Farmacêutico. Posteriormente, regressa à Indústria Farmacêutica como 
Business Manager na área dos over-the-counter. Docente, desde 2001, nas áreas do Marketing, Comunicação e Vendas, é professor adjunto convidado na Escola Superior de Hotelaria e Turismo do Estoril exercendo ainda atividade como formador e consultor em comunicação e marketing. Morada institucional: Escola Superior de Hotelaria e Turismo do Estoril, Departamento de Gestão, Av. Condes de Barcelona, n. ${ }^{\circ}$ 808, 2769-510 Estoril, Portugal.

Submetido em 2 maio 2017

Aceite em 30 outubro 2017 
Anexo 1. Questionário

\section{O impacto da Geração Millennials na comunicação do recurso turístico}

*Obrigatório

1. Qual o seu ano de nascimento? *

Marcar apenas uma oval

Inferior a 1982

Entre 1982 e 2005

Superior a 2005

2. Qual o género? *

Marcar apenas uma oval

Masculino

Feminino

3. Como considera a utilização que faz da Internet? *

Marcar apenas uma oval

$1 \quad 2 \quad 3 \quad 4 \quad 5$
Nada frequente $\square \subset \bigcirc \bigcirc$ Muito frequente

4. Gosta de viajar? *

Marcar apenas uma oval

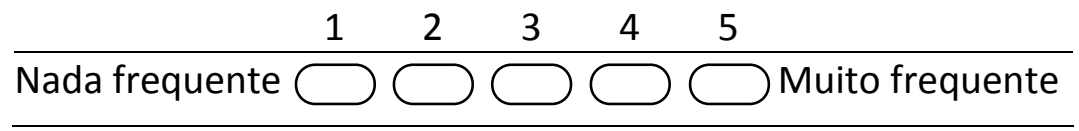

5. Costuma viajar? *

Marcar apenas uma oval

Nada frequente $\square{ }^{1} \bigodot^{3} \overbrace{}^{4} \bigodot^{5}$ Muito frequente

6. Quando viaja, torna-se determinante ter acesso à Internet? * 
Marcar apenas uma oval

$\frac{1}{\text { Nada frequente } \square \subset \bigcirc \bigcirc \text { Muito frequente }}$

7. Quando viaja é importante que a viagem tenha uma forte componente de novas experiências? *

Marcar apenas uma oval

$\Longrightarrow \operatorname{sim}$

Não

8. Quando viaja é fundamental partilhar elementos da viagem nas redes sociais? * Marcar apenas uma oval

$\bigcirc \operatorname{sim}$

Não

9. Durante a viagem costuma recorrer á informação da Internet/redes sociais para identificar/explorar novos recursos turísticos? *

Marcar apenas uma oval

$1 \quad 2 \quad 3 \quad 4 \quad 5$
Nada frequente $\square \bigcirc \bigcirc \bigcirc$ Muito frequente

10. Desfrutar de novas experiências é determinante para a marcação da viagem? * Marcar apenas uma oval

$\operatorname{Sim}$

Não

11. A Internet é determinante para a escolha de um determinado recurso turístico antes ou durante a viagem? ${ }^{*}$

Marcar apenas uma oval

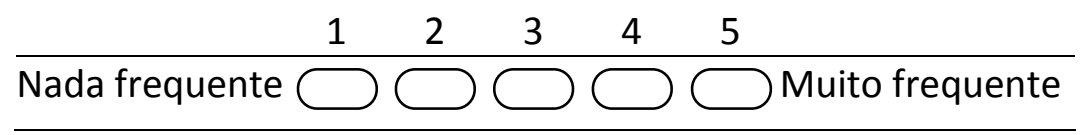

Obrigado pela sua participação 